\title{
Expansive Residual Soils and Their Possible Stabilisation by Soil Mixing
}

\author{
Rajeshwar Goodary ${ }^{1}$, Gisele Lecomte ${ }^{2}$, Miraniaina Adriamalala ${ }^{3}$, Anoop Aujayeb ${ }^{1}$ \\ ${ }^{1}$ Université des Mascareignes, Mauritius \\ Avenue de la Concorde, Roches Brunes, Rose Hill,Mauritius \\ rgoodary@udm.ac.mu \\ ${ }^{2}$ Université de Limoges SPCTS Research Laboratory \\ 12 Rue Atlantis, 87068 Limoges Cedex, France \\ Gisele.lecomte@unilim.fr \\ ${ }^{3}$ Institut Supérieur de Technologie d'Antananarivo \\ Antananarivo, Madagascar \\ miraniaina2@yahoo.fr
}

\section{Extended Abstract}

Expansive soils cause serious structural engineering challenges all over the globe, with damages related to soil movement underneath foundations. These formations undergo important volume change associated with changes in moisture contents, manifesting as swell or shrinkage. Generally, their scatterings depend mainly on the geology of the site and also on genetic of the parent material, prevailing climatic and hydro-geological conditions. Various published papers show that the behaviour of expansive soils, solicited to loadings, are to much extent, common for all locations and seem alarming. Stabilisation of expansive soils is one among the various measures adopted to limit the soil movement underneath structures by decreasing the swelling pressure of these soils. Recent research on this topic has revealed satisfactory ground improvement when expansive soils of volcanic origin, particularly Dark Magnesium Clay (DMC) is stabilized with various conventional binders like lime, cement, fly ash and coarse sand [1].

The aim of this research is to establish an appropriate mix comprising two different clays, one belonging to the family of montmorillonite, well known for its expansive nature and another one, known for being very obedient non swelling soil of kaolinite family, that will yield a composite soil with acceptable swelling and mechanical properties.

This paper proposes an all new concept of stabilisation of problematic expansive residual soil, Dark Magnesium Clay (DMC) of volcanic origin, occurring on the island of Mauritius, by soil mixing. DMC is a residual soil derived from eruption products of the old volcanic series, known for its disorderly geotechnical behaviour, mainly caused by the presence of montmorillonite clay component [2]. Specimens from these soils, stabilised with various extents of conventional additives, namely cement, lime and fly ash have shown that addition of an optimum amount of the stabiliser yields maximum unconfined compressive strength value up to $5.5 \mathrm{MPa}[3,4]$. However, it must be recognised that the application of these results is technically and materially expensive.

The proposed new concept of stabilisation by soil mixing will definitely reduce cost and it consists of partial replacement of the expansive raw material (DMC) by a non-expansive soil containing mainly kaolinitic clay, sampled from locations of the intermediate volcanic series, also occurring on the island of Mauritius. Complete characterisation of both materials, namely BET specific surface area in the range of $79-83.4 \mathrm{~m}^{2} / \mathrm{g}$, SEM imaging, XRD and XRF analyses have revealed positive indications of a possible interaction between these two clay families [5]. Extensive investigation is currently underway and interim results are deemed to be conclusive.

In this study, gradual replacement of DMC by variable percentages of non expansive kaolinite soil, reveals fluctuations of swelling pressure values in the range of $4.2-10.4 \mathrm{kPa}$, which is deemed significant. This concept also confirms that two soils, when coexisting within the same mass at certain moisture and density conditions, share not only their physical and classification properties which are often arithmetically correlated, but also the nonphysical interaction between the two different clays further helps to improve the soil mechanical behaviour, making the resulting material acceptable for civil engineering purposes. 


\section{References}

[1] R. Goodary et G. L. Lecomte-Nana, C. Petit, D. Smith, "Investigation of the strength properties of cement stabilised soils of volcanic origin," Construction and Building Materials, vol. 28, pp. 592-598, 2012.

[2] V. Proag, The geology and water resources of Mauritius. Mauritius: Mahatma Gandhi Institute, 1995.

[3] R. Goodary, R. Beeharry, R. Ramlogun, S. Horpibulsuk, G. Lecomte, "Effect of Fly Ash on Strength and Compressibility of Dark Magnesium Clay," in Proceedings of Advances in Civil Engineering for Sustainable Development, Thailan, 2014, pp. 437-442.

[4] R. Goodary, A. Chinkulkijniwat, R. Vatanivongs, R. Beeharry, A. Aujayeb, "An attempt to determine a Suitable Stabiliser for Expansive Soils of Volcanic Origin," in Proceedings of the Seventh International Conference on Geotechnique, Construction Materials and Environment, Mie, Japan, 2017, pp. 108-113.

[5] R. Goodary, G. Lecomte, M. Adriamalala, "Characterisation of residual soils of volcanic origin and its possible implications for soil stabilization" in Proceedings of $3^{\text {rd }}$ World Congress on Civil, Structural, and Environmental Engineering (CSEE'18), Budapest, Hungary, 2018. 